starts the chain over again, every $(r+1)$ st draw will be scored. This circuit is used for raising matrices to powers without employing control cards.

Dow Chemical Co.

ASCHER OPLER

Pittsburg, Calif.

${ }^{1}$ This is actually sampling without replacement and therefore does not strictly conform to the MARKOV process originally described. However, if the ratio of the number of punched cards to the order of the matrix is very large, nonreplacement has negligible effect on the remaining transition probabilities until the exhaustion of the deck approaches.

${ }^{2}$ H. Hotelling, "Some new methods in matrix calculation," Ann. Math. Stat. v. 14, 1943, p. 1-34.

${ }^{3}$ The IBM 101 statistical machine should be able to invert matrices up to the 30th order because of its selector capacity. Calif.

${ }^{4}$ Random numbers on punched cards are available from the Rand Corp., Santa Monica,

\title{
Computing Logical Truth with the California Digital Computer
}

1. Introduction. A problem which occasionally arises and in quite surprisingly diverse fields of endeavor is the computation of a truth table for a sentence built up of simple sentences connected by the simple sentential connectives. The problem is to find the truth value of the complete sentence for all combinations of truth values for the component sentences. If the complete sentence is a combination of $n$ two-valued sentences, then it itself is two-valued and $2^{n}$ possible conditions must be considered. Thus if the number of different component sentences is at all large, an extremely tedious computation is necessary.

Since the computation itself is performed in a routine manner, the possibility of using a high-speed, automatic computer to carry through the details suggests itself. Indeed, a machine for this purpose (the KalinBurkhart Logical-Truth Calculator) has already been built. ${ }^{1}$ It seems desirable, however, to investigate the possibility of solving these problems using general-purpose, digital computers as many of these will be in operation within the next few years. With this in mind, a program for truth-table calculation is worked out in the following for the California Digital Computer [MTAC, v. 5, p. 57-61]. The general plan should be applicable to any digital computer.

Most problem-solving programs require three basic routines. First the solution of the problem with a given set of data, second storing the result at the proper location in the memory, and third altering the data as required for the next computation. These will be discussed in subsequent sections.

Since the details of a computation program depend to a considerable extent on the characteristics of the computer for which it is developed, a brief description of the operations needed and available in the California Digital Computer (commonly called Caldic) will be presented. Other operations than those described are also available, but the discussion will not be complicated by describing them.

The program and data are given to the machine in the form of holes punched in a standard teletype tape. Results are printed out of the machine on a similar tape. Numerical data and results are in the form of decimal numbers which are used by the machine in a binary-coded form. The fact 
that numbers available to the operator are decimal is of importance in programming problems. This is particularly true of problems of the sort considered here which are essentially binary in nature. The numbers contain ten decimal digits and algebraic sign.

Before computation starts, data and orders are all transferred from the tape to the internal memory of the machine. This transfer takes approximately 18 milliseconds per number. The internal memory is a magnetic drum with a capacity of 10000 , ten digit numbers. Each memory position is identified by a four digit, decimal number. No differentiation is made between orders and numbers as far as the memory is concerned. The number stored in a memory box is not altered by any operation except that of putting another number in the box.

The first two digits in an order identify the operation to be performed. (The operator sees and uses them as letters, the machine as numbers.) The next four digits usually are the address of the operand in the memory. Exceptions will be discussed with the particular operations concerned. The final four digits are zeros.

The results of computations appear in the A register. It takes a special order to transfer them to the memory if this is necessary before another operation is to be performed.

The other register of interest is the order counter. The last entry on the input tape is a four digit number which is stored in the order counter and is the address of the first order. Thereafter as each order is completed the number in the order counter is increased by one to give the address of the next order. An exception is when a special order is used to change the number in the order counter.

The operations of interest are described in the following. The time for the operation should be understood to be the average time for a large number of random repetitions of the operation.

1. ad $M$. Average time 17.6 milliseconds. $M$ is a four digit number. Add the number in the memory box $M$ to the number in the $A$ register. This operation takes proper account of the algebraic signs of the two numbers to be added. In case the operation causes the A register to overflow, the machine stops unless the next order is the cp order. (See below.) At the completion of the ad operation the sum stands in the $A$ register but without the overflowing digit if such exists.

2. su M. Average time $\mathbf{1 7 . 6}$ milliseconds. Subtract the number in the memory box $M$ from the number in the A register. At the end of the operation the difference stands in the $A$ register. The remarks about sign and overflow under ad apply here also.

3. mh M. Average time 32.4 milliseconds. Multiply the number in memory box $\mathrm{M}$ by the number in the $\mathrm{A}$ register. This operation takes proper account of the algebraic sign of the two factors. It proceeds as if the decimal point is just to the left of each of the two factors. Therefore no overflow can occur.

4. tm M. Average time 17.3 milliseconds. Transfer the number in the A register to the memory box $M$. This operation leaves the A register clear.

5. sl $\mathrm{n}$. Average time 9.1 milliseconds. $\mathrm{n}$ is a four digit number with the first three digits always zero. Shift the number in the A register $n$ 
columns to the left. The first $\mathrm{n}$ digits after the sign are lost and $\mathrm{n}$ zeros are added at the right.

6. sr $\mathrm{n}$. Average time 8.8 milliseconds. $\mathrm{n}$ same as in the sl operation. Shift the number in the A register $n$ columns to the right. The $\mathrm{n}$ right hand digits are lost and $\mathrm{n}$ zeros are inserted after the sign.

7. cp $n$. Average time 8.8 milliseconds. $n$ is any four digit number. If an overflow occurred during the preceding operation, replace the number in the order counter by $\mathrm{n}$. Otherwise ignore this order.

8. sp n. Average time 8.8 milliseconds. $\mathrm{n}$ is any four digit number. Replace the number in the order counter by $n$.

9. ca M. Average time $\mathbf{1 7 . 5}$ milliseconds. Clear the address part of the order in the memory box $M$ and add the remainder of the order to the number in the $A$ register.

10. po M. Average time 1117.2 milliseconds. Print out the number in memory box $M$.

In general some of the above orders would also involve an additional register, the $\mathrm{R}$ register. However, in all the computations discussed in this paper the $\mathrm{R}$ register will hold nothing but zeros so may be ignored.

2. Problem Solution. In the following discussion marks used to distinguish a thing from its name will be omitted unless necessary to avoid ambiguities.

The operations on or between sentences to be considered are: negation, conjunction, disjunction, material implication, and equivalence. For purposes of the following discussion the word, combination, will represent any one of the latter four.

It will be convenient to make use of the following conventional terms in describing the problem solution. A schema is the result of writing in a row the following symbols in any order: $(),, p_{j}$, and the signs for negation and the various combinations. The sign, $p_{j}$, represents the various component sentences, $j$ taking on various integral values to distinguish between them. Only well-formed schemas, i.e. schemas in which the parentheses are used to give meaningful groupings, will be used.

The various $p_{j}$ 's are, by definition, schemas of zero order. A schema of order $n+1$ is constructed either by putting a negation sign before a schema of order $\mathrm{n}$ (which itself must be set off by parentheses) or by forming a combination of two schemas (each set off by parentheses) one of which is of order $n$ and the other of which is of order not greater than $n$.

It is assumed that the truth values of all schemas of zero order are available. Computation proceeds first by computing the truth values of schemas of order one. Then from the values of schemas of order zero and of order one the truth values of all schemas of order two can be calculated. This process continues until the complete schema has been evaluated. The result is transferred to the memory, the $p_{j}$ 's are altered to the next set of values to be used, and the process is repeated.

This may be illustrated by the following example. Suppose the fifth order schema

$$
\left(\left(p_{1} \rightarrow p_{0}\right) \wedge\left(\left(\left(p_{0} \wedge p_{1}\right) \wedge \sim p_{3}\right) \rightarrow p_{2}\right)\right) \wedge\left(\left(p_{2} \rightarrow p_{1}\right) \wedge\left(\sim p_{0} \rightarrow \sim p_{3}\right)\right)
$$

is to be evaluated. (Parentheses around individual variables and their negations are omitted.) Let $a_{j}$ represent schemas of order one, $b_{j}$ schemas 
of order two, and so on. Then

$$
\begin{aligned}
& a_{1} \leftrightarrow\left(p_{1} \rightarrow p_{0}\right) \\
& a_{2} \leftrightarrow\left(\sim p_{3}\right) \\
& a_{3} \leftrightarrow\left(p_{2} \rightarrow p_{1}\right) \\
& a_{4} \leftrightarrow\left(\sim p_{0}\right) \\
& a_{5} \leftrightarrow\left(p_{0} \wedge p_{1}\right)
\end{aligned}
$$

$$
\begin{aligned}
b_{1} \leftrightarrow\left(a_{5} \wedge a_{2}\right) \\
b_{2} \leftrightarrow\left(a_{4} \rightarrow a_{2}\right) \\
c_{1} \leftrightarrow\left(b_{2} \wedge a_{3}\right) \\
c_{2} \leftrightarrow\left(b_{1} \rightarrow p_{2}\right) \\
d_{1} \leftrightarrow\left(c_{2} \wedge a_{1}\right) \\
e_{1} \leftrightarrow\left(d_{1} \wedge c_{1}\right)
\end{aligned}
$$

Within any order-group any order of calculation may be used. The order shown is convenient since $a_{5}, b_{2}, c_{2}$, and $d_{1}$ are used only in the succeeding computation and thus need not be transferred to the memory. This possibility should always be exploited since in complicated problems it can lead to appreciable savings in computation time.

It remains to work out the evaluation of the negation and combinations. Many procedures have been tried, and those tabulated below require less computation time than any others considered. The times given include transfer from and to memory which may sometimes be avoided as discussed above. The operations to be performed follow from left to right in sequence. The symbols $p$ and $q$ are used for the component sentences. The results of the operations for the various cases are tabulated below the operation. The symbol ( $x$ ) indicates "the address in the memory of the number $x . "$ The symbol C(M) indicates "the contents of the memory box M." The symbol $0 \times 1$ indicates " $x$ zero's followed by the digit 1. "

Negation (52.5 milliseconds)

\begin{tabular}{|c|c|c|c|c|c|c|c|c|c|c|c|}
\hline D & $q$ & $\operatorname{ad}(p)$ & $\operatorname{ad}(q)$ & $\operatorname{ad}(98)$ & ср0008 & $\operatorname{ad}(01)$ & ср0009 & s10002 & $\operatorname{ad}(01)$ & $\operatorname{tm} \mathbf{M}$ & $\mathrm{C}(\mathrm{M}$ \\
\hline 00 & 00 & 00 & 00 & 98 & 98 & 99 & 99 & 00 & 01 & 00 & 01 \\
\hline 0 & 01 & 00 & 01 & 99 & 99 & 1.00 & 00 & & & & 00 \\
\hline & 00 & 01 & 01 & 99 & 99 & 1.00 & 00 & & & & 00 \\
\hline & 01 & 01 & 02 & 1.00 & 00 & & & & & 00 & 01 \\
\hline & rcous & 0001 & 0002 & 0003 & 0004 & 0005 & 0006 & 0007 & 0008 & 0009 & \\
\hline
\end{tabular}

p $\operatorname{ad}(01)$ su(p) tm M C(M)

$\begin{array}{lllll}0 & 01 & 01 & 00 & 01\end{array}$

$\begin{array}{lllll}01 & 01 & 00 & 00 & 00\end{array}$

Conjunction (76.4 milliseconds)

$\begin{array}{lllllll}\mathrm{p} & \mathrm{q} & \mathrm{ad}(\mathrm{p}) & \mathrm{mh}(\mathrm{q}) & \mathrm{sl} 0002 & \mathrm{tm} \mathrm{M} & \mathrm{C}(\mathrm{M}) \\ 00 & 00 & 00 & 0000 & 00 & 00 & 00 \\ 00 & 01 & 00 & 0000 & 00 & 00 & 00 \\ 01 & 00 & 01 & 0000 & 00 & 00 & 00 \\ 01 & 01 & 01 & 0001 & 01 & 00 & 01\end{array}$

Disjunction (88.0 milliseconds)

$\begin{array}{lllllllll}\mathrm{p} & \mathrm{q} & \mathrm{ad}(\mathrm{p}) & \operatorname{ad}(\mathrm{q}) & \operatorname{ad}(09) & \mathrm{sr} 0009 & \mathrm{~s} 10008 & \operatorname{tm} \mathrm{M} & \mathrm{C}(\mathrm{M}) \\ 00 & 00 & 00 & 00 & 09 & 0^{9} 0 & 00 & 00 & 00 \\ 00 & 01 & 00 & 01 & 10 & 0^{9} 1 & 01 & 00 & 01 \\ 01 & 00 & 01 & 01 & 10 & 0^{9} 1 & 01 & 00 & 01 \\ 01 & 01 & 01 & 02 & 11 & 0^{9} 1 & 01 & 00 & 01\end{array}$

Material Implication (88.0 milliseconds)

$\begin{array}{lllllllll}\mathrm{p} & \mathrm{q} & \operatorname{ad}(\mathrm{q}) & \mathrm{su}(\mathrm{p}) & \operatorname{ad}(10) & \mathrm{sr} 0009 & \mathrm{sl} 0008 & \operatorname{tm} \mathrm{M} & \mathrm{C}(\mathrm{M}) \\ 00 & 00 & 00 & 00 & 10 & 0^{91} & 01 & 00 & 01 \\ 00 & 01 & 01 & 01 & 11 & 0^{91} & 01 & 00 & 01 \\ 01 & 00 & 00 & -01 & 09 & 0^{91} & 00 & 00 & 00 \\ 01 & 01 & 01 & 00 & 10 & 0^{9} 1 & 01 & 00 & 01\end{array}$

Equivalence (109.8 milliseconds) 
It will be noticed that 01 is the truth value of a true sentence and 00 is the truth value of a false sentence. The zero in the first place simplifies the computation of the implication and has no effect on other computations.

3. Handling of Results. Since results consist of a single digit, it is possible to store ten of them in one memory box. Thus the first answer may be put in the left hand digit position, the second in the next to the left and so on until the memory box is filled. Then the contents of the box may be printed out, the box cleared, and the process repeated.

Storing ten answers in each box reduces the number of print operations by a factor of ten which is desirable since printing is by far the slowest of the machine operations.

Printing during computations makes the results available during computation which may be convenient. Also if the machine breaks down during computation, it will not be necessary to recalculate completely.

4. Altering Data. In order to make use of the advantages of automatic machine calculation, the machine itself should compute all but the initial data. In this problem the data are in the form of (binary) truth values and it is desirable to carry out the computation for all possible combinations of truth values.

Let the truth value ( 0 or 1 ) of each component sentence be $p_{j}$ where $j$ ranges over the values from 0 to $n-1, n$ being the number of component sentences to be considered. Construct a binary number $k$ the left hand (or most significant) digit being the result of writing the value of $p_{n-1}$, the next most significant digit being the result of writing the value of $p_{n-2}$, and so on. The least significant digit will be the result of writing the value of $p_{0}$. All combinations are covered if $k$ starts as zero and then is increased by unity for each computation until every digit of $k$ is one.

In machines using binary arithmetic this procedure can be worked out quite readily. The machine being considered here uses decimal arithmetic which complicates the problem somewhat. The procedure finally adopted makes use of the theorem ${ }^{2}$ which follows. For economy in writing, " $p_{j}$ " will be considered equivalent to "the result of writing the value of $p_{j}$."

Definition. A binary number $k$ is defined as the array

$$
p_{n-1} p_{n-2} \cdots p_{1} p_{0} \text {. }
$$

Theorem. The number $k$ is replaced by $k+1$ if and only if for every $j$ (if $0 \leq j \leq n-1$, then $p_{j}$ is replaced by $1-p_{j}$ if and only if for every $m$ (if $0 \leq m<j$ then $\left.p_{m}=1\right)$ ). Or more compactly

$$
k(\mathrm{~B}) k+1 \leftrightarrow_{j}\left(0 \leq j \leq n-1 \rightarrow\left(p_{j}(\mathrm{~B}) 1-p_{j} \leftrightarrow_{m}\left(0 \leq m<j \rightarrow p_{m}=1\right)\right)\right)
$$

(It is understood that $p_{j}$ remains unchanged unless it is replaced by $1-p_{j}$ by the above rule, and that at every step $p_{0}$ is replaced by $1-p_{0}$.)

This procedure is programmed quite readily.

5. Terminating the Problem. The machine will not stop, of course, unless it has definite instructions to do so. These may be obtained readily by adding another digit $p_{n}$ to the left of $k$. This is zero throughout the computation but will change to one when a one is added to the last value of $k$ to be considered. Thus in the preceding section when the largest value of $j$ satisfying the last equivalence equals $n$, the computation is finished and the machine may be instructed to stop. 
The situation may occur in which all possible combinations of truth values need not be considered. For instance, only true or only false values of a particular sentence may be of interest. In this case this value will be held as a constant (and not stored in the memory with the other p's) and $n$ will be one less than the number of component sentences.

6. The Program. The operations discussed in the four preceding sections are embodied in the flow chart, figure 1, and together make up the program. When the flow chart is worked out in sufficient detail, the program is readily

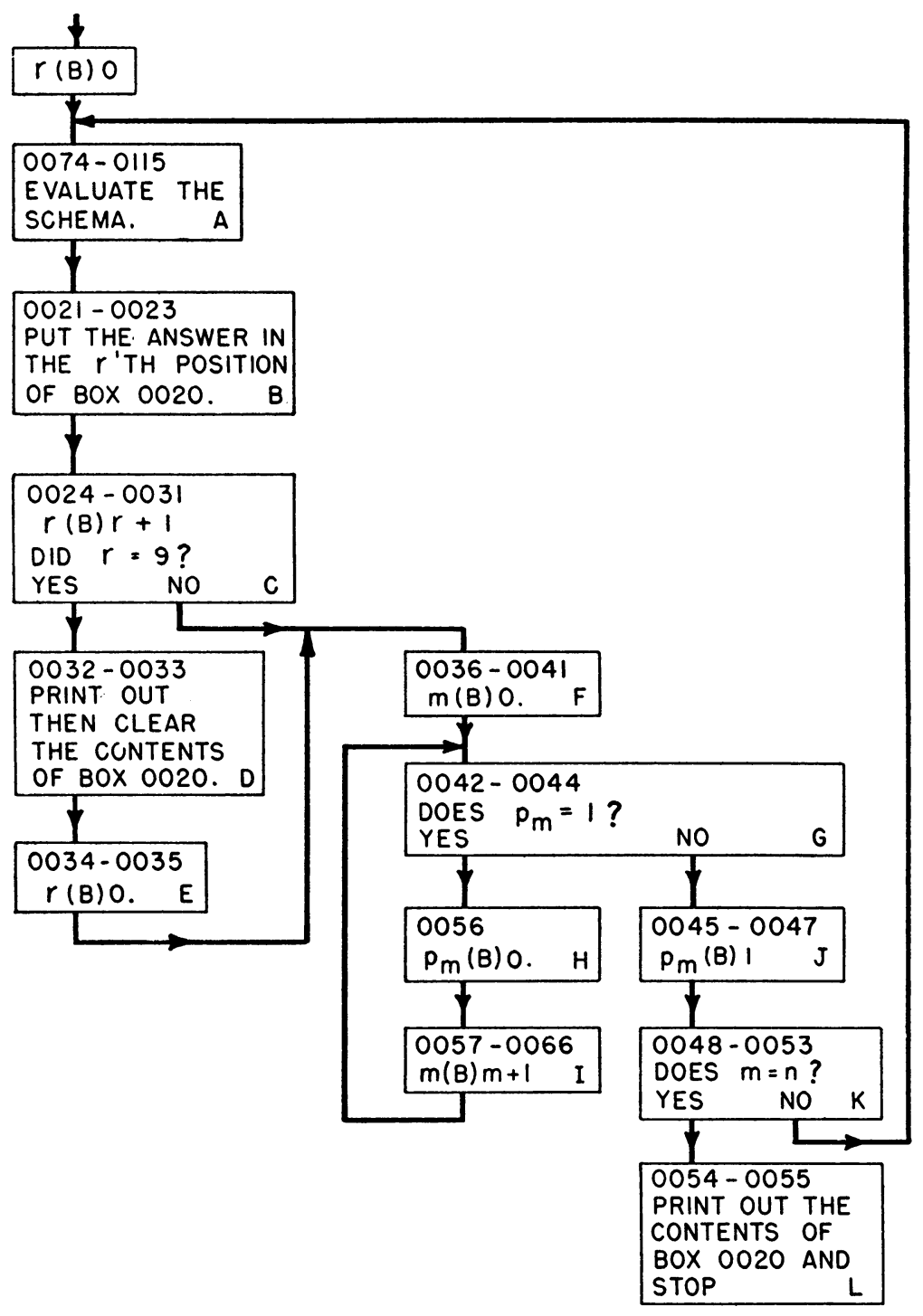

FIGURE 1

FLOW CHART FOR THE PROGRAM 
coded or translated into a language to which the machine will respond. A code for this problem is given in Appendix $I$.

Within the rectangles of the flow chart are first the memory boxes in which the instructions to perform the operation demanded in the rectangle are to be stored (for the particular code given in Appendix I). Secondly the operation to be performed is given. In case the operation to be performed is in the form of a question, the alternative answers to the question indicate the paths by which the computation will proceed. The capital letter in the rectangle identifies the operation for the discussion below.

The expression $x$ (B) $y$ means that at this point $y$ is to be substituted for $x$ wherever $x$ appears in the program. It may be read " $x$ becomes $y$."

Operations $\mathrm{D}$ and $\mathrm{E}$ must be performed a number of times equal to the largest digit which is less than $0.1 \times 2^{n}$. Operations $H$ and I must be performed a number of times equal to $2^{n+1}-(n+2)$. Operation $L$ must be performed once. All other operations must be performed $2^{n}$ times.

Operation $\mathrm{A}$ is self-explanatory. Operations $\mathrm{B}, \mathrm{C}, \mathrm{D}$, and $\mathrm{E}$ are for handling the results. Operations $F, G, H, I$, and $J$ take care of altering the data. Operations $\mathrm{K}$ and $\mathrm{L}$ are for terminating the problem.

7. Conclusion. The program given here was developed and coded with the idea in mind of minimizing the changes necessary in going from one problem to another. It was thought that 19 variables is beyond the limits of practicality (for this machine, at least, since 19 variables would take over six days of machine time). As long as no more than 19 variables are used the instructions in memory boxes 0000 to 0072 inclusive will apply to any problem. Memory box 0073 will contain the number $1.00-0.01 n$ (decimal point to the left of the most significant figure of numbers in the memory). This will be used to terminate the computation. Starting with memory box 0074 the schema is evaluated as discussed in section 2 . The schema given there as an example is the one coded in Appendix I. The truth value of the schema is finally left in the left hand digit position of the $A$ register. (Note that the routines of section 2 leave the value in the position next to the left hand one so that the last operation must be altered accordingly.) Then the command $\mathrm{sp} 0021$ is used to go to operation $\mathrm{B}$ of figure 1.

In preparation for working these problems a master tape going only through 0072 will be prepared. For a particular problem this will be duplicated and the additional orders needed will be added on the duplicate. Then the entire contents of the tape will be fed into the machine, the $A$ and $\mathrm{R}$ registers cleared, and the machine started with the order counter at 0074 .

Using the average times given in section $I$ the problem time is

$$
T=0.91 \times 2^{n}-0.18 n+0.75+0.077 c \times 2^{n} \text { seconds, }
$$

where $c$ is the number of connectives in the schema. It should be emphasized that this is a rough estimate and depends on the assumption that on the average it will take half a drum revolution to find the memory box requested. In the example given here $n=4$ and $c=11\left(\sim p_{3}\right.$ need be calculated only once) yielding $T=26$ seconds. (It is understood, of course, that this short example would be worked more economically manually.)

Available data on the Kalin-Burkhart machine are rather sparse, but it would be interesting to compare its operation with that of the program 
developed here. It would appear that the Kalin-Burkhart machine will compute the problem a little faster than will the Caldic. The Caldic, however, is rather slow as electronic computers go. Problem preparation time should be about the same. On the other hand the Kalin-Burkhart machine is limited to problems with 12 component sentences and 11 connectives. With the Caldic the number of component sentences is limited only by the time for which the machine is available for the particular problem and there appears to be no practical limitation on the number of connectives.

Appendix I. The Coded Program. These quantities will be fed in sequence into the memory the first in to box 0000 , the second into box 0001 , and so on until the list is exhausted. It is understood that the machine will treat letters as digits and that each number will be filled out with zeros to make ten digits. Every quantity has a plus sign attached. Under each memory box number is given its contents.

\begin{tabular}{|c|c|c|c|c|c|c|c|}
\hline $\begin{array}{l}0000 \\
0\end{array}$ & $\begin{array}{l}0001 \\
0\end{array}$ & $\begin{array}{l}0002 \\
0\end{array}$ & $\begin{array}{l}0003 \\
0\end{array}$ & $\begin{array}{l}0004 \\
0\end{array}$ & $\begin{array}{l}0005 \\
0\end{array}$ & $\begin{array}{l}0006 \\
0\end{array}$ & $\begin{array}{l}0007 \\
0\end{array}$ \\
\hline $\begin{array}{l}0008 \\
0\end{array}$ & $\begin{array}{l}0009 \\
0\end{array}$ & $\begin{array}{l}0010 \\
0\end{array}$ & $\begin{array}{l}0011 \\
0\end{array}$ & $\begin{array}{l}0012 \\
0\end{array}$ & $\begin{array}{l}0013 \\
0\end{array}$ & $\begin{array}{l}0014 \\
0\end{array}$ & $\begin{array}{l}0015 \\
0\end{array}$ \\
\hline $\begin{array}{l}0016 \\
0\end{array}$ & $\begin{array}{l}0017 \\
0\end{array}$ & $\begin{array}{l}0018 \\
0\end{array}$ & $\begin{array}{l}0019 \\
0\end{array}$ & $\begin{array}{l}0020 \\
0\end{array}$ & $\begin{array}{l}0021 \\
\text { sr0000 }\end{array}$ & $\begin{array}{l}0022 \\
\text { ad0020 }\end{array}$ & $\begin{array}{l}0023 \\
\text { tm0020 }\end{array}$ \\
\hline $\begin{array}{l}0024 \\
\text { ad0021 }\end{array}$ & $\begin{array}{l}0025 \\
\text { sl0005 }\end{array}$ & $\begin{array}{l}0026 \\
\text { ad0069 }\end{array}$ & $\begin{array}{l}0027 \\
\text { cp0032 }\end{array}$ & $\begin{array}{l}0028 \\
\text { sr0005 }\end{array}$ & $\begin{array}{l}0029 \\
\text { ca0021 }\end{array}$ & $\begin{array}{l}0030 \\
\text { tm0021 }\end{array}$ & $\begin{array}{l}0031 \\
\text { sp0036 }\end{array}$ \\
\hline $\begin{array}{l}0032 \\
\text { po0020 }\end{array}$ & $\begin{array}{l}0033 \\
\text { tm0020 }\end{array}$ & $\begin{array}{l}0034 \\
\text { ca0021 }\end{array}$ & $\begin{array}{l}0035 \\
\text { tm0021 }\end{array}$ & $\begin{array}{l}0036 \\
\mathrm{ca} 0043\end{array}$ & $\begin{array}{l}0037 \\
\text { tm0042 }\end{array}$ & $\begin{array}{l}0038 \\
\text { ca0047 }\end{array}$ & $\begin{array}{l}0039 \\
\text { tm0047 }\end{array}$ \\
\hline $\begin{array}{l}0040 \\
\mathrm{ca} 0056\end{array}$ & $\begin{array}{l}0041 \\
\text { tm0056 }\end{array}$ & $\begin{array}{l}0042 \\
\text { ad0000 }\end{array}$ & $\begin{array}{l}0043 \\
\text { ad0071 }\end{array}$ & $\begin{array}{l}0044 \\
\text { cp0056 }\end{array}$ & $\begin{array}{l}0045 \\
\text { sl0002 }\end{array}$ & $\begin{array}{l}0046 \\
\text { ad0067 }\end{array}$ & $\begin{array}{l}0047 \\
\text { tm0000 }\end{array}$ \\
\hline $\begin{array}{l}0048 \\
\text { ad0042 }\end{array}$ & $\begin{array}{l}0049 \\
\text { si0004 }\end{array}$ & $\begin{array}{l}0050 \\
\text { ad0073 }\end{array}$ & $\begin{array}{l}0051 \\
\text { cp0054 }\end{array}$ & $\begin{array}{l}0052 \\
\text { s10002 }\end{array}$ & $\begin{array}{l}0053 \\
\text { sp0074 }\end{array}$ & $\begin{array}{l}0054 \\
\text { po0020 }\end{array}$ & $\begin{array}{l}0055 \\
\text { STOP }\end{array}$ \\
\hline $\begin{array}{l}0056 \\
\text { tm0000 }\end{array}$ & $\begin{array}{l}0057 \\
\text { ad0042 }\end{array}$ & $\begin{array}{l}0058 \\
\text { ad0072 }\end{array}$ & $\begin{array}{l}0059 \\
\text { tm0042 }\end{array}$ & $\begin{array}{l}0060 \\
\text { ad0047 }\end{array}$ & $\begin{array}{l}0061 \\
\text { ad0072 }\end{array}$ & $\begin{array}{l}0062 \\
\text { tm0047 }\end{array}$ & $\begin{array}{l}0063 \\
\text { ad0056 }\end{array}$ \\
\hline $\begin{array}{l}0064 \\
\text { ad0072 }\end{array}$ & $\begin{array}{l}0065 \\
\text { tm0056 }\end{array}$ & $\begin{array}{l}0066 \\
\text { sp0042 }\end{array}$ & $\begin{array}{l}0067 \\
01\end{array}$ & $\begin{array}{l}0068 \\
09\end{array}$ & $\begin{array}{l}0069 \\
10\end{array}$ & $\begin{array}{l}0070 \\
98\end{array}$ & $\begin{array}{l}0071 \\
99\end{array}$ \\
\hline $\begin{array}{l}0072 \\
000001\end{array}$ & $\begin{array}{l}0073 \\
96\end{array}$ & $\begin{array}{l}0074 \\
\text { ad0000 }\end{array}$ & $\begin{array}{l}0075 \\
\text { su0001 }\end{array}$ & $\begin{array}{l}0076 \\
\text { ad0069 }\end{array}$ & $\begin{array}{l}0077 \\
\text { sr0009 }\end{array}$ & $\begin{array}{l}0078 \\
\text { s10008 }\end{array}$ & $\begin{array}{l}0079 \\
\text { tm0116 }\end{array}$ \\
\hline $\begin{array}{l}0080 \\
\text { ad0067 }\end{array}$ & $\begin{array}{l}0081 \\
\text { su0003 }\end{array}$ & $\begin{array}{l}0082 \\
\text { tm0117 }\end{array}$ & $\begin{array}{l}0083 \\
\text { ad0001 }\end{array}$ & $\begin{array}{l}0084 \\
\text { su0002 }\end{array}$ & $\begin{array}{l}0085 \\
\text { ad0069 }\end{array}$ & $\begin{array}{l}0086 \\
\text { sr0009 }\end{array}$ & $\begin{array}{l}0087 \\
\text { sl0008 }\end{array}$ \\
\hline $\begin{array}{l}0088 \\
\text { tm0118 }\end{array}$ & $\begin{array}{l}0089 \\
\text { ad0067 }\end{array}$ & $\begin{array}{l}0090 \\
\text { su0000 }\end{array}$ & $\begin{array}{l}0091 \\
\text { tm0119 }\end{array}$ & $\begin{array}{l}0092 \\
\text { ad0000 }\end{array}$ & $\begin{array}{l}0093 \\
\text { mh0001 }\end{array}$ & $\begin{array}{l}0094 \\
\text { sl0002 }\end{array}$ & $\begin{array}{l}0095 \\
\text { mh0117 }\end{array}$ \\
\hline $\begin{array}{l}0096 \\
\text { sl0002 }\end{array}$ & $\begin{array}{l}0097 \\
\text { tm0120 }\end{array}$ & $\begin{array}{l}0098 \\
\text { ad0117 }\end{array}$ & $\begin{array}{l}0099 \\
\text { su0119 }\end{array}$ & $\begin{array}{l}0100 \\
\text { ad0069 }\end{array}$ & $\begin{array}{l}0101 \\
\text { sr0009 }\end{array}$ & $\begin{array}{l}0102 \\
\text { sl0008 }\end{array}$ & $\begin{array}{l}0103 \\
\text { mh0118 }\end{array}$ \\
\hline $\begin{array}{l}0104 \\
\text { sl0002 }\end{array}$ & $\begin{array}{l}0105 \\
\text { tm0121 }\end{array}$ & $\begin{array}{l}0106 \\
\text { ad0002 }\end{array}$ & $\begin{array}{l}0107 \\
\text { su0120 }\end{array}$ & $\begin{array}{l}0108 \\
\text { ad0069 }\end{array}$ & $\begin{array}{l}0109 \\
\text { sr0009 }\end{array}$ & $\begin{array}{l}0110 \\
\text { s10008 }\end{array}$ & $\begin{array}{l}0111 \\
\text { mh0116 }\end{array}$ \\
\hline $\begin{array}{l}0112 \\
\text { s10002 }\end{array}$ & $\begin{array}{l}0113 \\
\mathrm{mh} 0121\end{array}$ & $\begin{array}{l}0114 \\
\text { sl0003 }\end{array}$ & $\begin{array}{l}0115 \\
\text { sp0021 }\end{array}$ & & & & \\
\hline
\end{tabular}




\section{Appendix II. Glossary.}

$n$ the number of component sentences in the complete schema.

$p_{j}$ the $j$ th component sentence.

$a_{j}, b_{j}$, etc. the $j$ th component schema of order 1,2 , etc.

$c$ the number of connectives in the schema.

$T$ estimated computing time in seconds.

1 (or 01 ) in the proper context the truth value of a true sentence.

0 (or 00 ) in the proper context the truth value of a false sentence.

$x$ (B) $y \quad y$ is to replace $x$ wherever $x$ appears.

(h) address in the memory of the number $h$.

$\mathrm{C}(\mathrm{M})$ contents of the memory box $\mathrm{M}$.

$\sim$ It is not the case that ...

$\wedge$... and ...

$\checkmark \ldots$ or ....

$\rightarrow$ If ... then ...

$\leftrightarrow \quad \ldots$ if and only if ...

$x$ For every $x \ldots$

Wilton R. Aвbott

Univ. of California

Berkeley

1 Edmund C. Berkeley, Giant Brains, New York, 1949, Ch. 9.

${ }^{2}$ GeORGE W. Patrerson, Logical Syntax and Transformation Rules. Moore School of Electrical Engineering, Research Division Report 50-8, Univ. of Pennsylvania, Philadelphia, 1949.

\section{On the Accuracy of Runge-Kutta's Method}

1. Introduction. While the accuracy of the most frequently used methods of integrating differential equations is fairly well known, that of the RungeKutta method does not seem to be too well established; except for a formula in Bieberbach's text ${ }^{1}$ on differential equations there are no references pertaining to the error inherent in the Runge-Kutta method to be found in the standard textbooks on this subject.

Since this method may be employed quite advantageously in many cases of practical interest it is important to have on hand an estimate of the error. The purpose of the following sections is to provide such an estimate. As a comparison shows, the bound derived for this error seems to be somewhat better than the one cited by Bieberbach.

2. Runge-Kutta's Fourth Order Method. In trying to find that solution of the differential equation

$$
d y / d x=f(x, y), \quad y\left(x_{0}\right)=y_{0},
$$

at $x_{1}=x_{0}+h$, which agrees with the exact Taylor expansion about $x_{0}$ :

(2) $y\left(x_{1}\right)=y_{0}+h y_{0}{ }^{\prime}+h^{2}\left(y_{0}^{\prime \prime} / 2\right)+h^{3}\left(y_{0}{ }^{\prime \prime \prime} / 6\right)+h^{4}\left(y_{0}^{\text {iv }} / 24\right)$ $+h^{5}\left(y_{0} v / 120\right)+\cdots$ 